\title{
C - reactive protein and interleukin - 6 levels among human immunodeficiency virus -infected patients with dysglycemia in Tanzania
}

Lilian Nkinda $^{1,2^{*}}$ (D), Kirtika Patel ${ }^{2}$, Benson Njuguna ${ }^{3}$, Jean Pierre Ngangali, ${ }^{2,4}$, Peter Memiah ${ }^{5}$, George M. Bwire ${ }^{1}$ Mtebe V. Majigo', Mucho Mizinduko ${ }^{6}$, Sonak D. Pastakia ${ }^{7}$ and Eligius Lyamuya ${ }^{1}$

\begin{abstract}
Background: Chronic inflammation has been associated with dysglycemia among people living with HIV (PLHIV). There is however, limited data regarding this phenomenon in sub-Sahara Africa (SSA). Therefore we assessed the levels of C-reactive protein (CRP) and Interleukin 6 (IL-6) on a cohort of PLHIV and its associations with dysglycemia in Tanzania.

Methods: We conducted a cross-sectional study at the Infectious Disease Clinic (IDC) in Tanzania from March to May 2018. Purposive sampling was used to identify participants who had an undetectable viral load, were on 1st line anti-retroviral therapy (ART) and had an overnight fast. The WHO stepwise approach for non-communicable disease (NCD) surveillance was used to collect data. Fasting blood glucose and blood glucose after $75 \mathrm{~g}$ oral glucose load was measured, and Enzyme-linked immunosorbent assay (ELISA) was used to test for inflammatory markers (IL-6 and CRP). Associations were explored using the Chi square test and binary logistic regression was performed to estimate the odds ratios. A p-value less than 0.05 was considered statistically significant.

Results: A total of 240 participants were enrolled. Forty two percent were overweight/obese (> $\left.25 \mathrm{~kg} / \mathrm{m}^{2}\right), 89 \%$ had a high waist to height ratio. The median ART duration was $8(5-10)$ years. The prevalence of dysglycemia among our cohort of PLHIV was 32\%. High CRP was associated with a 2.05 increased odds of having dysglycemia OR 2.05 $(1.15-3.65)(p=0.01)$. Taking stavudine was associated with a 1.99 odds of having dysglycemia OR 1.99 (1.04-3.82) $(p=0.03)$.We did not find a significant association between IL-6 and dysglycemia.
\end{abstract}

Conclusion: High CRP and taking stavudine were significantly associated with dysglycemia among PLHIV with undetectable viral load.

Keywords: CRP, HIV related inflammation, Diabetes, Pre-diabetes, Tanzania, Sub-Saharan Africa

\section{Background}

Improved access to antiretroviral therapy (ART) and advances in HIV care in sub-Saharan Africa (SSA) has significantly increased life expectancy for people living with HIV (PLHIV) [1]. However, with aging and more time on ART, PLHIV are now more susceptible to non-

\footnotetext{
* Correspondence: lilynkinda@gmail.com

'Department of Microbiology and Immunology, Muhimbili University of Health and Allied Sciences, P.O box 65001, Dares Salaam, Tanzania

${ }^{2}$ Department of Immunology, Moi University, P.O. Box 4606-30100, Eldoret, Kenya

Full list of author information is available at the end of the article
}

communicable diseases (NCD) such as dysglycemia, that is, the presence of impaired fasting glucose (IFG), impaired glucose tolerance (IGT), or type 2 diabetes mellitus (T2DM) [2, 3]. Published reports from SSA reveal an escalating burden of dysglycemia among PLHIV $[2,4,5]$, up to four times more compared to HIV negative controls [5]. This may be due to a mix of HIV related risk factors including chronic systemic inflammation [6, 7], use of ART such as stavudine [8], zidovudine [8], and protease inhibitors [4], and traditional risk factors such

(c) The Author(s). 2019 Open Access This article is distributed under the terms of the Creative Commons Attribution 4.0 International License (http://creativecommons.org/licenses/by/4.0/), which permits unrestricted use, distribution, and reproduction in any medium, provided you give appropriate credit to the original author(s) and the source, provide a link to the Creative Commons license, and indicate if changes were made. The Creative Commons Public Domain Dedication waiver (http://creativecommons.org/publicdomain/zero/1.0/) applies to the data made available in this article, unless otherwise stated. 
as physical inactivity, harmful alcohol use, smoking, overweight, and obesity [9-11].

It has been hypothesized that dysglycemia in PLHIV may be a result of an ongoing chronic inflammatory response [12, 13]. Several studies from high income countries (HIC) among PLHIV have demonstrated correlation between high levels of pro-inflammatory cytokines such as IL-6, CRP and tumour necrosis factor (TNF $\alpha$ ), and dysglycemia, independent of body mass index (BMI) and age $[12,13]$. In SSA, inflammation is reported to increase the risk of mortality $[7,14]$ and cardiovascular disease (CVD) among PLHIV [15], however, data on inflammation and dysglycemia is limited. Furthermore, extrapolating findings from HIC to PLHIV in SSA may not be reliable because of the existence of heterogeneity between inflammatory markers and type 2 diabetes based on race/ethnicity [16], a lower prevalence of traditional risk factors such as obesity in SSA compared to HIC which may influence systemic inflammation [17], and a higher background inflammatory state in the general SSA population [17]. SSA regional data on the association between chronic inflammation and dysglycemia among PLHIV is therefore needed.

The inflammatory markers of concern are many [18] but due to the biological and laboratory reproducibility of IL-6 and CRP, and their ability to predict the occurrence of non AIDS events [19], this study assessed the levels of CRP and IL-6 among PLHIV with dysglycemia in Tanzania.

\section{Methods}

\section{Study site}

We conducted this study at the Infectious Disease Clinic (IDC) at Ilala municipality in Dar es salaam, Tanzania. IDC operates a large care and treatment centre for PLHIV which attends to approximately 100 adult PLHIV per working day.

\section{Study design and study population}

A cross-sectional study was carried out from March to May 2018. We included participants who were adult (above 18 years of age) PLHIV, had an overnight fast for at least $8 \mathrm{~h}$, were currently on 1st line ART per applied guidelines in the setting [20], and had attained an undetectable viral load within the last 6 months. We excluded pregnant women, patients who had been on anti-inflammatory drugs within the last 3 months and those on 2nd line ART regimen including protease inhibitors (PI).

\section{Sample size and sampling technique}

The sample size calculation was based on a reported prevalence of $17.4 \%$ of elevated CRP among patients with diabetes [18], and was calculated using Fisher's formula. A minimum sample size of 220 was required to identify a prevalence of elevated CRP and IL- 6 among HIV patients with dysglycemia, adjusted to 240 assuming a $10 \%$ non-response rate.

Purposive sampling was used for recruitment.

\section{Data collection}

On enrolment, the WHO stepwise approach for NCD surveillance was used for data collection [21]. Additional information on CD4 count before ART initiation, after 6 months on ART, and the current CD4 count (within 6 months before study enrolment) was obtained from the files. The type of ART and duration on ART was also obtained from participants' files. Demographic and behavioural characteristics such as age, sex, family history of diabetes, physical activity, and alcohol and smoking habits were collected through face to face interviews by a trained nurse counsellor. Physical measurements such as weight, height, and waist circumference were also taken by a trained nurse. Blood pressure was measured when a patient was seated and relaxed, using an Omron M2 (HEM-7121-E) automatic blood pressure device. Readings were taken two times consistently from the left arm, at three minutes interval.

\section{Cut off used for physical measurements}

Waist to height ratio (WHR) was calculated, with a cut off of $>50 \%$ being considered to represent an elevated WHR [22]. BMI was calculated based on weight and height and the following cut-offs were used: underweight $\left(\mathrm{BMI}<18 \mathrm{~kg} / \mathrm{m}^{2)}\right.$, normal $\left(\mathrm{BMI} \geq 18 \mathrm{~kg} / \mathrm{m}^{2}\right.$ and $\leq$ $25 \mathrm{~kg} / \mathrm{m}^{2}$ ), overweight (BMI $>25 \mathrm{~kg} / \mathrm{m}^{2}$ and $<30 \mathrm{~kg} / \mathrm{m}^{2}$, and obese $\left(B M I \geq 30 \mathrm{~kg} / \mathrm{m}^{2}\right)$. For ease of analysis, those who were overweight were combined with those who were obese, and those with normal BMI were combined with those who were underweight. Blood pressure was considered elevated if the average reading was $\geq 140 / 90 \mathrm{mmHg}$.

\section{Laboratory blood sample collection}

Venous blood samples were taken for measurements, fasting and $2 \mathrm{~h}$ post $75 \mathrm{~g}$ oral glucose load from each participant. Serum was separated immediately after collection and measurements were done on the Cobas-integra $400+$ Roche chemistry analyser within $30 \mathrm{~min}$ of collection. The remaining blood was stored in cryo vials at $-80^{\circ} \mathrm{C}$. The stored blood was used for IL- 6 and CRP analysis using ELISA reader Multiskan Ascent reader 354-90593.

\section{Determination of dysglycemia}

Dysglycemia was diagnosed by the presence of any of the following: i) impaired fasting glucose (IFG), defined as fasting blood glucose of 6.1 to $6.9 \mathrm{mmol} / \mathrm{L}$ and 2-h glucose $<7.8 \mathrm{mmol} / \mathrm{L}$ ); ii) impaired glucose tolerance (IGT), 
defined as fasting blood glucose $<7.0 \mathrm{mmol} / \mathrm{L}$ and 2 -h glucose $\geq 7.8$ and $<11.1 \mathrm{mmol} / \mathrm{L}$; and iii) diabetes mellitus (DM), defined as fasting blood glucose $\geq 7.0 \mathrm{~mol} / \mathrm{L}$ or a glucose level $\geq 11.1 \mathrm{~mol} / \mathrm{l} 2 \mathrm{~h}$ after a $75 \mathrm{~g}$ oral glucose load [5, 23].

\section{Laboratory procedure for IL-6 using ELISA}

Indirect ELISA for IL-6 was performed using reagents from R\&D systems, Catalogue number PD6050; we adopted their procedure as well. Briefly, a standard solution was prepared and serially diluted into five concentrations each half of the previous starting from concentrations of $300 \mathrm{pg} / \mathrm{ml}$. Then $100 \mu \mathrm{l}$ of sample, standard and controls were added into a pre-coated 96 well plate containing IL-6 monoclonal antibody in duplicates. Human IL- 6 conjugate was added followed by a substrate solution after washing. Finally a stop solution was added changing the color of the well content into yellow from blue. Optical density was determined using a $450 \mathrm{~nm}$ and corrected by using a 630 wavelength.

A standard curve of mean absorbance of each standard against its concentration was plotted, the best fit line was determined by regression analysis. A $y=m x+c$ equation was generated. The rest of the results were obtained by substituting $y$ as the mean value of absorbance and calculating for $\mathrm{X}$ (concentration) for each patient result.

\section{Expected values}

Concentration of IL- 6 beyond $5 \mathrm{pg} / \mathrm{ml}$ was considered high [24].

\section{Laboratory procedure for CRP using ELISA}

Indirect ELISA for CRP was performed using reagents from R\&D systems, Catalogue number PD6050; we adopted their procedure as well. Briefly, a standard solution was prepared and serially diluted into five concentrations each half of the previous starting from a concentrations of $50 \mathrm{ng} / \mathrm{ml}$, the samples were also diluted 100 folds $(10 \mu \mathrm{l}$ of sample $+990 \mu \mathrm{l}$ of diluents). Then $50 \mu \mathrm{l}$ of sample, standard and controls were added into pre-coated 96 well plates containing CRP monoclonal antibody in duplicates. Human CRP conjugate was added followed by a substrate solution after washing. Finally a stop solution was added changing the color of the well content into yellow from blue. Optical density was determined using a $450 \mathrm{~nm}$ and corrected by using a 630 wavelength.

A standard curve of mean absorbance of each standard against its concentration was plotted, the best fit line was determined by regression analysis. A $y=m x+c$ equation was generated. The rest of the results were obtained by substituting $y$ as the mean value of absorbance and calculating for $\mathrm{X}$ (concentration) for each patient result. The concentration was then times by the dilution factor (100).

\section{Expected values}

CRP concentration above $10 \mathrm{mg} /$ litre was considered high [25].

\section{Data analysis}

Data from case report forms (CRFs) and ELISA reader were entered on an Excel spreadsheet and cleaned. Then data were exported to the statistical package for social sciences version 23 (SPSS software Chicago Inc., USA) for coding and statistical analysis. Descriptive statics were used to summarise participants' characteristics. Bivariate analysis was used to look for association between the studied variables and the outcome measure. All variables with a $p$ value $\leq 0.2$ were subjected to a multi variate analysis with logistic regression. The magnitude of association was measured using adjusted odds ratio, and 95\% confidence interval. A $p$-value $<0.05$ was considered statistically significant.

\section{Results}

\section{Participant characteristics}

The characteristics of 240 participants who were enrolled and completed study procedures are summarised in Table 1. The mean age was $47 \pm 10$ years with the majority of participants being female $(n=181[75 \%])$. About 58(42\%) participants were overweight/obese (> 25 $\left.\mathrm{kg} / \mathrm{m}^{2}\right), 215(89 \%)$ had high waist to height ratio and $53(22 \%)$ had high systolic blood pressure. Ninety (37\%) were involved in vigorous activities as part of their work and $110(46 \%)$ walked/cycled for more than $10 \mathrm{~min}$ to work for an average of 3 days a week.

The mean baseline CD4 count was $288 \mathrm{cells} / \mu \mathrm{l}$ and 15(7\%) had previously began ART treatment with a high viral load (1000+). After six months on ART, the mean CD4 count was 410 cells/ $\mu$ l. The current CD4 count after a median ART duration of 8 years (IQR 5-10) was 520 cells/ $/$ l. Seventy one (29\%) were on a Stavudine $(\mathrm{d} 4 \mathrm{~T})$ based regimen while $86(35 \%)$ were on a Zidovudine based regimen. All participants reported good adherence to ART.

\section{Sample prevalence of dysglycemia, CRP and IL-6}

Among the study participants, 76(32\%) had a dysglycemia, where $48(20 \%)$ had IFG, $26(11 \%)$ had IGT and $2(0.8 \%)$ had T2DM. No prior known diabetes cases were encountered during the study period. High CRP was observed among $80(33 \%)$ participants. Among participants with dysglycemia, high CRP was observed in 34(44\%). High IL-6 levels were observed in 17(7\%) participants. Among participants with dysglycemia, high IL-6 was observed in 7(9\%) (Table 2). 
Table 1 Participants' characteristics

\begin{tabular}{|c|c|}
\hline Variables & Value $(n=240)$ \\
\hline Age (mean $\pm S D)$ & $47 \pm 10$ \\
\hline \multicolumn{2}{|l|}{ Education level (\%) } \\
\hline No formal & $29(12 \%)$ \\
\hline Primary & $151(63 \%)$ \\
\hline Secondary and above & $60(25 \%)$ \\
\hline Female & $181(75 \%)$ \\
\hline Family history of diabetes type 2 & $19(9 \%)$ \\
\hline Current smoker (last 30 days) & $5(3 \%)$ \\
\hline Consumed alcohol in the last 30 days & $36(15 \%)$ \\
\hline Vigorous activity & $90(37 \%)$ \\
\hline Walking/bicycle (> 10 min) & $110(46 \%)$ \\
\hline \multicolumn{2}{|l|}{ BMI (\%) } \\
\hline Normal+Underweight & $130(58 \%)$ \\
\hline Overweight +Obese & $58(42 \%)$ \\
\hline \multicolumn{2}{|l|}{ Waist to height ratio (\%) } \\
\hline$>50 \%$, (high) & 215(89\%) \\
\hline High blood pressure $(\geq 140 / 90 \mathrm{mmHg})$ & $53(22 \%)$ \\
\hline \multicolumn{2}{|l|}{ Baseline VL (Copies/ml) (\%) } \\
\hline 0-999 & 210(93\%) \\
\hline $1000+$ & $15(7 \%)$ \\
\hline Baseline CD4 (mean \pm SD) & $288 \pm 231$ \\
\hline CD 4 count after 6 months on ART(mean \pm SD) & $410 \pm 223$ \\
\hline Current CD4 (mean \pm SD) & $520 \pm 236$ \\
\hline \multicolumn{2}{|l|}{ Type or ART } \\
\hline Stavudine based regimen & $71(29 \%)$ \\
\hline Zidovudine based regimen & $86(35 \%)$ \\
\hline Tenofovir based regimen & $83(34 \%)$ \\
\hline Efavirenz containing regimen & $205(86 \%)$ \\
\hline Median ART duration in years (IQR) & $8(5-10)$ \\
\hline
\end{tabular}

Table 2 Prevalence of dysglycemia, CRP and IL-6

\begin{tabular}{ll}
\hline Variable & $\mathrm{N}(\%)$ \\
\hline Dysglycemia & $76(32 \%)$ \\
Impaired fasting glucose (IFG) & $48(20 \%)$ \\
Impaired glucose tolerance (IGT) & $26(11 \%)$ \\
Diabetes mellitus type 2 (DM) & $2(0.8 \%)$ \\
High CRP & $80(33 \%)$ \\
Dysglycemia with High CRP & $34(44 \%)$ \\
High IL-6 & $17(7 \%)$ \\
Dysglycemia with high IL-6 & $7(9 \%)$ \\
\hline
\end{tabular}

\section{Bivariate analysis}

Among all the variables only CRP was significantly associated with dysglycemia ( $p$-value of 0.01 ). Other variables with a $p$-value of $<0.2$ included CRP level ( $p$-value 0.01), systolic blood pressure ( $p$-value 0.07 ), and being on a stavudine based regimen ( $p$-value 0.06 ) were subjected to multivariate analysis. Results of bivariate analysis are shown in Table 3.

\section{Multivariate analysis}

Multivariate analysis was performed to adjust for potential confounders with $p$ value $<0.2$. While IL-6 did not meet this threshold, it was added in the adjusted model due to its potential to drive the CRP result [26]. On the multivariate analysis (Table 4$)$, high CRP (>10 mg/dl) OR 2.05 (1.15-3.65), ( $p$-value 0.01) and taking stavudine OR 1.99 (1.04-3.82), ( $p$-value 0.03) were significantly associated with dysglycemia.

\section{Discussion}

The prevalence of dysglycemia among our sampled PLHIV population on ART was $32 \%$. We found that high CRP or being on a stavudine based regimen were significantly associated with having dysglycemia in multivariate analysis. A trend towards increased WHR (89\%) and being overweight/obese BMI (44\%), was observed among those with dysglycemia, but these did not reach statistical significance.

Although the prevalence of overt DM was low at $0.8 \%$, the prevalence of pre-diabetes mellitus (pre-DM) comprising of IFG and IGT was high at $31.7 \%$. In a recent review, the prevalence of DM and pre-DM was estimated to range from 1 to $26 \%$ and $19-47 \%$ among PLHIV in SSA [17]. The highest prevalence of DM and pre-DM was reported in Cameroon at 47 and $27 \%$ respectively among ART naive PLHIV, but no association with inflammatory markers was done [2]. In Tanzania, Maganga et al. found 18 and 14.7\% DM and pre-DM prevalence amongst PLHIV respectively, however this burden could not be explained by known risk factors such as BMI, age, or ART duration among those receiving therapy, suggesting a potential role of inflammation [5]. Estimates from the HIV negative population in rural communities in northern Tanzania reported a comparatively lower prevalence of DM, and pre-DM, 2.8 and 2.5\% respectively [27] which highlights the increased risk of dysglycemia among PLHIV. Furthermore, PrayGod et al. reported $1.5 \%$ and over $20 \%$ prevalence for DM and pre-DM respectively among underweight HIV-infected participants [28], and Mohammed et al. found a prevalence of 6.4 and $19.6 \%$ for DM and pre-DM respectively among Ethiopians [29]. While largely consistent, our study participants had longer times on ART (8 years vs 2 and 5 years) $[28,29]$. The consistently high prevalence of 
Table 3 Factors associated with dysglycemia in bivariate analysis

\begin{tabular}{|c|c|c|c|}
\hline Variable & $\begin{array}{l}\text { Dysglycemia } \\
\mathrm{N}(\%)\end{array}$ & $\begin{array}{l}\text { No dysglycemia } \\
\mathrm{N}(\%)\end{array}$ & $\begin{array}{l}\text { Chi square test } \\
\text { ( } p \text { value) }\end{array}$ \\
\hline \multicolumn{4}{|l|}{ Age } \\
\hline Below 20 years & $1(1.3)$ & $1(0.6)$ & \multirow[t]{5}{*}{$1.958(0.7)$} \\
\hline 20-29 years & $2(2.6)$ & $8(4.9)$ & \\
\hline 30-49 years & $45(57.7)$ & $98(60.5)$ & \\
\hline 50-64 years & $25(32.1)$ & $49(30.2)$ & \\
\hline $65-74$ years & $5(6.4)$ & $6(3.7)$ & \\
\hline \multicolumn{4}{|l|}{ Gender } \\
\hline Male & $23(29.5)$ & $36(22.2)$ & \multirow[t]{2}{*}{$1.499(0.2)$} \\
\hline Female & $55(70.5)$ & $126(77.8)$ & \\
\hline \multicolumn{4}{|l|}{ BMI } \\
\hline $\begin{array}{l}\text { Normal + } \\
\text { Underweight }\end{array}$ & $44(57)$ & $96(59)$ & \multirow[t]{2}{*}{$0.175(0.6)$} \\
\hline Obese + Overweight & $34(43.5)$ & $66(41)$ & \\
\hline \multicolumn{4}{|l|}{ Waist to height ratio } \\
\hline$<50 \%$, normal & $8(10.3)$ & $17(10.5)$ & \multirow[t]{2}{*}{$0.003(0.9)$} \\
\hline$>50 \%$, abnormal & 70 (89.7) & $145(89.5)$ & \\
\hline $\begin{array}{l}\text { Blood pressure } \\
(\geq 140 / 90 \mathrm{mmHg})\end{array}$ & $22(28 \%)$ & $31(19 \%)$ & $2.5(0.07)$ \\
\hline \multicolumn{4}{|l|}{ CRP } \\
\hline Low & $44(56.5)$ & $116(71.6)$ & \multirow[t]{2}{*}{$5.470(0.01)$} \\
\hline High & $34(43.6)$ & $46(28.4)$ & \\
\hline \multicolumn{4}{|l|}{ IL 6} \\
\hline Low & $71(91)$ & $152(93.8)$ & \multirow[t]{2}{*}{$0.628(0.4)$} \\
\hline High & $7(9)$ & $10(6.2)$ & \\
\hline \multicolumn{4}{|l|}{ Current smoker } \\
\hline No & 77 (98.7) & $153(97.5)$ & \multirow[t]{2}{*}{$0.364(0.5)$} \\
\hline Yes & $1(1.3)$ & $4(2.5)$ & \\
\hline \multicolumn{4}{|c|}{ Consumed alcohol in the last 30 days } \\
\hline No & $65(83.3)$ & $139(85.8)$ & \multirow[t]{2}{*}{$0.252(0.6)$} \\
\hline Yes & $13(16.7)$ & $23(14.2)$ & \\
\hline \multicolumn{4}{|l|}{ Vigorous activity } \\
\hline No & $50(64.1)$ & $100(61.7)$ & \multirow[t]{2}{*}{$0.127(0.7)$} \\
\hline Yes & $28(35.9)$ & $62(38.3)$ & \\
\hline \multicolumn{4}{|l|}{ Parent Type 2 Diabetes } \\
\hline No & $72(92.3)$ & $148(91.9)$ & \multirow[t]{2}{*}{$0.011(0.9)$} \\
\hline Yes & $6(7.7)$ & $13(8.1)$ & \\
\hline $\begin{array}{l}\text { Stavudine containing } \\
\text { regimen }\end{array}$ & $17(21.8)$ & $54(33.3)$ & $3.365(0.06)$ \\
\hline $\begin{array}{l}\text { Thymidine analogue } \\
\text { (D4t or AZT) }\end{array}$ & $49(62.8)$ & $108(66.7)$ & $0.344(0.5)$ \\
\hline
\end{tabular}

pre-DM presents an opportunity for research on interventions to interrupt disease progression, as well as the urgent integration of routine screening for dysglycemia among PLHIV in SSA.
In our study, high CRP was associated with a 2 fold increased odds of having dysglycemia among PLHIV on 1st line ART with undetectable viral load. In SSA, studies on inflammation and dysglycemia among PLHIV are limited to a follow up cross sectional study [28] which did not find association between dysglycemia and either baseline or follow-up CRP after 2-3 years on ART. Inability to mount a CRP response could be explained by low CD4 count of $127 \pm 99 \mu \mathrm{l} / \mathrm{ml}$ in their study as compared to $520 \pm 236 \mu \mathrm{l} / \mathrm{ml}$ in the current study, as severe immunodeficiency $(<50 \mu \mathrm{l} / \mathrm{ml})$ is reported to significantly limit inflammatory response, in addition to an increased risk of death [30]. This is observed in the above study [28] where only $57 \%$ out of 478 were alive at trial conclusion [28]. Several studies from HIC have reported higher levels of CRP and IL- 6 to be associated with the incidence of dysglycemia [31, 32]. However how molecular mediators of inflammation lead to dysglycemia is not fully understood [33]. According to Lufti et al., immune inflammatory response may result to a change in metabolism by initiating insulin resistance in order to reduce energy consumption for body activities other than host defence [34]. Persistent inflammation among PLHIV due to inability to clear the virus or dysbiosis induce prolonged insulin resistance causing chronic restructure of metabolic pathways that may lead to diabetes [34, 35]. This is evidenced by a follow up study showing graded increases of high sensitive CRP (hs-CRP) and IL-6 to be associated with the increased risk of developing diabetes; those in the highest quartile of baseline plasma hsCRP had 5 times greater risk than those in the lowest quartile ( $\mathrm{HR}=5.13 ; 95 \% \mathrm{CI} 2.6-10.1)$, for those in the highest quartile of IL- 6 rates were 3 times greater than those in the lowest quartile (HR 3.45;95\% CI 1.91-6.23) [12]. Furthermore Brown et al. reported association between hs-CRP and incidence of diabetes at 48 weeks of ART initiation independent of known diabetes risk factors, however no significant associations with IL-6 were reported in this study [13]. These findings support chronic low-grade inflammation hypothesis in the development of DM, suggesting that CRP might be a useful marker in prediction of glucose abnormalities among PLHIV $[28,29]$, however, causation cannot be established through our current research design.

Of note, in this study, IL-6 had no association with dysglycemia. Weaker associations between dysglycemia and IL- 6 compared to dysglycemia and CRP have also been observed in other studies [12, 36]. This may be because IL-6 has a much lower half life in circulation compared to CRP [37]. On the other hand, there are studies that reported IL- 6 to be strongly associated to non AIDS events compared to CRP during HIV infection [38], therefore variability observed in our study may be due to chance. We did not find studies in SSA that 
Table 4 Factors associated with dysglycemia in Multivariate analysis

\begin{tabular}{lllll}
\hline Variable & Un adjusted OR $(95 \% \mathrm{Cl})$ & $P$ value & Adjusted OR $(95 \% \mathrm{Cl})$ & $P$ value \\
\hline CRP & $1.95(1.11-3.42)$ & 0.02 & $2.05(1.15-3.65)$ & 0.01 \\
IL 6 & $1.49(0.55-4.09)$ & 0.43 & $1.2(0.45-3.68)$ & 0.63 \\
Blood pressure $(\geq 140 / 90 \mathrm{mmHg})$ & $1.7(0.90-3.21)$ & 0.11 & $1.69(0.88-3.24)$ & 0.10 \\
Stavudine based regimen & $1.8(0.99-3.53)$ & 0.05 & $1.99(1.04-3.82)$ & 0.03 \\
\hline
\end{tabular}

looked at IL-6 as a potential risk factor for dysglycemia among PLHIV, and to the best of our knowledge, this is the first study that looked at both CRP and IL-6 and dysglycemia among SSA PLHIV.

Stavudine use was associated with a 1.99 fold risk of having dysglycemia. Twenty nine percent of our study participants were on this regimen despite WHO recommendations to discontinue the use of thymidine analogue NRTI [39]. Stavudine use has been consistently associated with insulin resistance and a 19\% increased risk of developing DM $[8,40]$. The proposed mechanism involves inhibition of enzyme DNA polymerase- $\gamma$ responsible for mitochondrial function [8]. This results to mitochondrial dysfunction that leads to insulin resistance [41]. Studies conducted among PLHIV have been complicated by the confounding effect of HIV infection where a reduction of mitochondrial DNA is observed in absence of ART [42]. However data from HIV uninfected populations have demonstrated a $52 \%$ reduction of muscle mitochondrial DNA after 1 month of stavudine exposure [43]. Therefore consumption of stavudine for PLHIV may exacerbate mitochondrial dysfunction, hastening the occurrence of diabetes. The risk is ever increasing with cumulative exposure. This was not observed in our study with a median ART duration of 8 years. Abrahams et al. [44] also did not find association with dysglycemia in PLHIV with a median duration of use of 6.8 years on stavudine. On the contrary, a 9 year follow up study in Senegal that involved participants who received stavudine among other regimens reported a $10 \%$ increased risk of dysglycemia after 4 years of treatment [45]. The majority of studies that have reported a lack of association between ART consumption and dysglycemia have had either a small sample size or a small number of different ART combinations [5].The overwhelming benefits of ART outweigh the occurrence of non AIDS events [46], therefore efforts to counteract the adverse events may be more useful to reduce the burden of co-morbidities.

Traditional risk factors for dysglycemia in PLHIV include: older age $[4,47]$, male gender $[9,48]$, family history of diabetes [49], higher BMI [9, 50], high WHR [51], smoking [52], alcohol consumption [52], hypertension [29] and physical inactivity [28]. We did not find a statistically significant association for any of the above with dysglycemia in this study. Our study participants were majority female $(75 \%)$, reported low prevalence of smoking (3\%), alcohol consumption (15\%), and family history of DM (9\%), which may also have limited our ability to find associations between these risk factors and dysglycemia. There was a trend towards increased WHR (89\%) and being overweight/obese BMI (42\%) among those with dysglycemia, but this did not reach statistical significance. Participants with dysglycemia were slightly younger with the majority falling in the 30-49 age category, however the association was also not statistically significant.

While our findings are among the few studies on inflammation and dysglycemia in Africa, they remain correlative. Research gaps that can be explored in the future include: i) conducting a longitudinal study that will further assess the relationship between inflammation and incident dysglycemia, and ii)intervention studies among the pre-DM PLHIV population to prevent disease progression to DM. Different interrupters can be explored such as nutrition, anti-inflammatory agents and lifestyle modifications.

One of the main limitations of this study was that $75 \%$ of study participants were female. It was challenging to get men to participate, possibly because of the $2 \mathrm{~h}$ wait period for the OGTT test. Poor male participation in health services is reported in several studies in Africa and this has been associated with a higher mortality among HIV positive males compared to females in SSA [53]. A small sample size may have also limited the ability to detect other significant associations. Finally, our study did not use high sensitive CRP (hsCRP) to measure CRP, which may have underestimated the burden of inflammation.

\section{Conclusion}

This study showed high CRP was significantly associated with dysglycemia among PLHIV with undetectable viral load. Taking stavudine was associated with increased odds of dysglycemia.

\section{Abbreviations}

ART: Antiretroviral therapy; BMl: Body mass index; CRFs: Case report forms; EACEA: Education, audiovisual and culture executive agency; HIC: High income countries; Hs-CRP: High sensitive C reactive protein; IL-6: Interlukin-6; MTRH: Moi teaching and referral hospital; NACP: National AIDS control program; NCD: Non communicable disease; NRTI: Nucleoside reverse transcriptase inhibitors; OGT: Oral glucose tolerance test; PLHIV: People 
living with HIV; SSA: Sub Sahara Africa; T2DM: Type 2 diabetes mellitus; TNF: Tumour necrosis factor; WHR: Waist height ratio

\section{Acknowledgements}

We are grateful to IDC nurses and phlebotomist for their priceless support during data collection; the authors also wish to acknowledge Mr. Zachariah Mtulo's assistance during laboratory sample analysis.

\section{Authors' contributions}

LN contributed in conception and design of the study, data collection, analysis of laboratory samples, and manuscript writing. KP, BN, SP, EL, contributed in design of the study and manuscript writing. MVM, GB and JPN contributed in data collection and manuscript writing. MM contributed in conception the study and manuscript writing, PM contributed in data analysis and manuscript writing. All authors have read and approved this manuscript.

\section{Funding}

This study was funded by the Intra Africa Academic mobility scheme scholarship, EACEA. Dr. Peter Memiah provided additional laboratory reagents which enabled analysis of inflammatory markers for all participants.

\section{Availability of data and materials}

All data used to draw conclusion of the study is provided in the manuscript.

\section{Ethics approval and consent to participate}

Ethical approval was obtained from the Institutional research and ethics committee of Moi University and Moi Teaching and Referral Hospital with approval number 0001963, as well as the Senate Research and Publications Committee at Muhimbili University of Health and Allied Sciences with reference number 2017-12-06/AEC/Nol.XII/86. Written informed consent was obtained from each participant.

\section{Consent for publication}

Not applicable.

\section{Competing interests}

The authors declare that they have no competing interest.

\section{Author details}

'Department of Microbiology and Immunology, Muhimbili University of Health and Allied Sciences, P.O box 65001, Dares Salaam, Tanzania. ${ }^{2}$ Department of Immunology, Moi University, P.O. Box 4606-30100, Eldoret, Kenya. ${ }^{3}$ Department of Pharmacy and Department of Cardiology, Moi Teaching and Referral Hospital, P.O Box 3-30100, Eldoret, Kenya. ${ }^{4}$ Rwanda National Reference Laboratory, P.O Box 4668, Kigali, Rwanda. ${ }^{5}$ Department of Public Health, University of West Florida, 11000 University Parkway, Pensacola, USA. ${ }^{6}$ Department of Epidemiology and Biostatistics, Muhimbili University of Health and Allied Sciences, P.O Box 65001, Dares Salaam, Tanzania. ${ }^{7}$ Purdue College of Pharmacy, Purdue Kenya Partnership, P.O Box 5760, Eldoret, Kenya.

\section{Received: 19 March 2019 Accepted: 11 July 2019} Published online: 22 July 2019

\section{References}

1. Kharsany ABM, Karim QA. HIV infection and AIDS in sub-Saharan Africa: current status, Challenges and Opportunities. Open AIDS J. 2016;10:34-48.

2. Ngatchou W, Lemogoum D, Ndobo P, Yagnigni E, Tiogou E, Nga E, et al. Increased burden and severity of metabolic syndrome and arterial stiffness in treatment-naïve HIV+ patients from Cameroon. Vasc Health Risk Manag. 2013;9:509-16.

3. Moyo D, Tanthuma G, Mushisha O, Kwadiba G, Chikuse F, Cary MS, et al. Diabetes mellitus in HIV-infected patients receiving antiretroviral therapy. SAMJ. 2014;104:40-2 scieloza.

4. Levitt NS, Peer N, Steyn K, Lombard C, Maartens G, Lambert EV, et al. Increased risk of dysglycaemia in south Africans with HIV; especially those on protease inhibitors. Diabetes Res Clin Pract. 2016;119:41-7.

5. Maganga E, Smart LR, Kalluvya S, Kataraihya JB. Glucose metabolism disorders, HIV and Antiretroviral Therapy among Tanzanian Adults 2015;150: $1-13$.
6. Slim J, Saling CF. A Review of Management of Inflammation in the HIV Population 2016;2016.

7. Drain PK, Kupka R, Msamanga GI, Urassa W, Mugusi F, Fawzi WW. C-reactive protein independently predicts HIV-related outcomes among women and children in a resource-poor setting. AIDS. 2007 Oct 1;21(15):2067-75.

8. Karamchand S, Leisegang R, Schomaker M, Maartens G, Walters L, Hislop M, et al. Risk Factors for Incident Diabetes in a Cohort Taking First-Line Nonnucleoside Reverse Transcriptase Inhibitor-Based Antiretroviral Therapy. Medicine (Baltimore). 2016;95(9):e2844 Lapadula. G, editor.

9. Chimbetete C, Mugglin C, Shamu T, Kalesan B, Bertisch B, Egger M, et al. New-onset type 2 diabetes mellitus among patients receiving HIV care at Newlands clinic, Harare, Zimbabwe: retrospective cohort analysis. Trop Med Int Heal. 2017;22(7):839-45.

10. Noumegni SRN, Nansseu JR, Ama VJM, Bigna JJ, Assah FK, Guewo-Fokeng $M$, et al. Insulin resistance and associated factors among HIV-infected patients in sub-Saharan Africa: a cross sectional study from Cameroon. Lipids Health Dis. 2017;16:148.

11. Anothaisintawee T, Reutrakul S, Van Cauter E, Thakkinstian A. Sleep disturbances compared to traditional risk factors for diabetes development: systematic review and meta-analysis. Sleep Med Rev. 2018;30:11-24.

12. Dooko CBA, De Wit S, Neuhaus J, Palfreeman A, Pepe R, Pankow JS, et al. Interleukin-6, high sensitivity C-reactive protein, and the development of type 2 diabetes among HIV positive patients taking antiretroviral therapy. J Acquir Immune Defic Syndr. 2014;67(5):538-46.

13. Brown TT, Tassiopoulos K, Bosch RJ, Shikuma C, McComsey GA. Association between systemic inflammation and incident diabetes in HIV-infected patients after initiation of antiretroviral therapy. Diabetes Care. 2010;33(10): 2244-9.

14. Ledwaba L, Tavel JA, Khabo P, Maja P, Qin J, Sangweni P, et al. Pre-ART levels of inflammation and coagulation markers are strong predictors of death in a south African cohort with advanced HIV disease. PLoS One. 2012; 7(3):e24243.

15. Muswe R, Oktedalen O, Zhou DT, Zinyando E, Shawarira-Bote S, StrayPedersen B, et al. Inflammatory markers and plasma lipids in HIV patients: a correlation analysis study. Open Biochem J. 2017;11:105-18.

16. Effoe VS, Correa A, Chen H, Lacy ME, Bertoni AG. High-sensitivity C-reactive protein is associated with incident type 2 diabetes among African Americans: the Jackson heart study. Diabetes Care. 2015;38(9):1694-700.

17. Njuguna B, Kiplagat J, Bloomfield GS, Pastakia SD, Vedanthan R, Koethe JR. Review Article Prevalence, Risk Factors, and Pathophysiology of Dysglycemia among People Living with HIV in Sub-Saharan Africa. 2018;2018(Dm).

18. Dallmeier D, Larson MG, Wang N, Fontes JD, Benjamin EJ, Fox CS. Addition of inflammatory biomarkers did not improve diabetes prediction in the community: the Framingham heart study. J Am Hear Assoc Cardiovasc Cerebrovasc Dis. 2012;1 (4):e000869.

19. Hearps AC, Martin GE, Rajasuriar R, Crowe SM. Inflammatory co-morbidities in HIV+ individuals: learning lessons from healthy ageing. Curr HIV/AIDS Rep. 2014;11(1):20-34

20. NACP. National Guidelines For The Sixth Edition October 2017. 2017:(October).

21. WHO. WHO STEPS Instrument for Chronic Disease. 2009;1-12.

22. Caminha TC, Ferreira HS, Costa NS, Nakano RP, Carvalho RE, Xavier AF Jr, Assunção ML. Waist-to-height ratio is the best anthropometric predictor of hypertension: a population-based study with women from a state of northeast of Brazil. Medicine. 2017;96(2):e5874.

23. World Health Organization. Definition and diagnosis of diabetes mellitus and intermediate hyperglycemia:Report of a WHO/IDF consultation. Production. 2006:1-52.

24. Koenig HG, Cohen HJ, George LK, Hays JC, Larson DB, Blazer DG. Attendance at religious services, Interleukin-6, and other biological parameters of immune function in older adults. Int J Psychiatry Med. 1997;27(3):233-50.

25. Yoon C, Chaisson LH, Patel SM, Allen IE, Drain PK, Wilson D, et al. Diagnostic accuracy of C-reactive protein for active pulmonary tuberculosis: a metaanalysis. Int J Tuberc Lung Dis. 2017;21(9):1013-9.

26. Sproston NR, Ashworth JJ. Role of C-reactive protein at sites of inflammation and infection. Front Immunol. 2018;9:754.

27. Miller B. Type 2 diabetes in the arumeru district of northern Tanzania: evaluation of prevalence and associated risk factors in rural communities. 2013.

28. PrayGod G, Changalucha J, Kapiga S, Peck R, Todd J, Filteau S. Dysglycemia associations with adipose tissue among HIV-infected patients after 2 years of antiretroviral therapy in Mwanza: a follow-up cross-sectional study. BMC Infect Dis. 2017;17(1):103. 
29. Mohammed AE, Shenkute TY, Gebisa WC. Diabetes mellitus and risk factors in human immunodeficiency virus-infected individuals at Jimma University specialized hospital, Southwest Ethiopia. Diab Metab Syndr Obes. 2015 Apr 15:8:197-206.

30. Vishwanath A, Quaiser S, Khan R. Role of high-sensitivity C-reactive protein measurements in HIV patients. Indian J Sex Transm Dis AIDS. 2016;37(2): 123-8.

31. Madsen T, Skou HA, Hansen VE, Fog L, Christensen JH, Toft E, et al. Creactive protein, dietary $n-3$ fatty acids, and the extent of coronary artery disease. Am J Cardiol. 2016;88(10):1139-42.

32. Lin N, Shi J, Li Y-M, Zhang X-Y, Chen Y, Calder PC, et al. What is the impact of $n-3$ PUFAs on inflammation markers in type 2 diabetic mellitus populations?: a systematic review and meta-analysis of randomized controlled trials. Lipids Health Dis. 2016;15:133.

33. Tutuncu Y, Satman I, Celik S, Dinccag N, Karsidag K, Telci A, et al. A Comparison of hs-CRP Levels in New Diabetes Groups Diagnosed Based on FPG , 2-hPG , or HbA1c Criteria. 2016;2016:12-7.

34. Luft VC, Schmidt MI, Pankow JS, Couper D, Ballantyne CM, Young JH, et al. Chronic inflammation role in the obesity-diabetes association: a case-cohort study. Diabetol Metab Syndr. 2013;5:31.

35. Lederman MM, Funderburg NT, Sekaly RP, Klatt NR, Hunt PW. Residual immune dysregulation syndrome in treated HIV infection. Adv Immunol. 2013;119:51-83.

36. Hu FB, Meigs JB, Li TY, Rifai N, Manson JE. Inflammatory Markers and Risk of Developing Type 2 Diabetes in Women. Diabetes, 2004. 53(3):693 LP-700.

37. Garvin P, Nilsson E, Ernerudh J, Kristenson M. The joint subclinical elevation of CRP and IL-6 is associated with lower health-related quality of life in comparison with no elevation or elevation of only one of the biomarkers. Qual Life Res. 2016;25(1):213-21 2015/07/21.

38. Borges ÁH, Groups for the ISS and E, O'Connor JL, groups for the ISS and E, Phillips AN, groups for the ISS and E, et al. Interleukin 6 is a stronger predictor of clinical events than high-sensitivity C-reactive protein or Ddimer during HIV infection. J Infect Dis. 2016;214(3):408-16.

39. WHO. Consolidated Guidelines on the Use of Antiretroviral Drugs for Treating and Preventing HIV Infection. 2015;(November):272.

40. Reid MJA, Tsima BM, Kirk B. Review Article HIV and diabetes in Africa 2012; $28-32$.

41. De Wit S, Sabin CA, Weber R, Worm SW, Reiss P, Cazanave C, et al. Incidence and Risk Factors for New-Onset Diabetes in HIV-Infected Patients. Diabetes Care. 2008;31(6):1224 LP-1229.

42. Garrabou G, López S, Morén C, Martínez E, Fontdevila J, Cardellach F, et al. Mitochondrial damage in adipose tissue of untreated HIV-infected patients. AIDS. 2011;25(2):165-70.

43. Fleischman A, Johnsen S, Systrom DM, Hrovat M, Farrar CT, Frontera W, et al. Effects of a nucleoside reverse transcriptase inhibitor, stavudine, on glucose disposal and mitochondrial function in muscle of healthy adults. Am J Physiol Endocrinol Metab. 2007;292(6):E1666-73.

44. Abrahams Z, Dave JA, Maartens G, Levitt NS. Changes in blood pressure, glucose levels, insulin secretion and anthropometry after long term exposure to antiretroviral therapy in south African women. AIDS Res Ther. 2015;12:24

45. Diouf A, Cournil A, Ba-Fall K, Ngom-Guèye NF, Eymard-Duvernay S, Ndiaye I, et al. Diabetes and hypertension among patients receiving antiretroviral treatment since 1998 in Senegal: prevalence and associated factors. ISRN AIDS. 2012;2012:621565.

46. Paula AA, Falcão MCN, Pacheco AG. Metabolic syndrome in HIV-infected individuals: underlying mechanisms and epidemiological aspects. AIDS Res Ther. 2013;10:32

47. Chaudhary R, Bliden KP, Garg J, Mohammed N, Tantry U, Mathew D, et al. Statin therapy and inflammation in patients with diabetes treated with high dose aspirin. J Diabetes Complicat. 2016;30(7):1365-70.

48. Dave JA, Lambert EV, Badri M, West S, Maartens G, Levitt NS. Effect of nonnucleoside reverse transcriptase inhibitor-based antiretroviral therapy on dysglycemia and insulin sensitivity in South African HIV-infected patients. JAIDS J Acquir Immune Defic Syndr. 2011;57(4):284-9.

49. Nansseu JR, Bigna JJ, Kaze AD, Noubiap JJ. Incidence and risk factors for prediabetes and diabetes mellitus among hiv-infected adults on antiretroviral therapy: a systematic review and meta-analysis. Epidemiology. 2018;29(3):431-41.

50. Isa SE, Oche AO, Kang'ombe AR, Okopi JA, Idoko JA, Cuevas LE, et al. Human immunodeficiency virus and risk of type 2 diabetes in a large adult cohort in Jos, Nigeria. Clin Infect Dis. 2016;63(6):830-5.
51. Husain NE, Noor SK, Elmadhoun WM, Almobarak AO, Awadalla H,

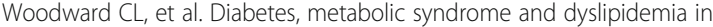
people living with HIV in Africa: re-emerging challenges not to be forgotten. HIV AIDS (Auckl). 2017;9:193-202.

52. Ikeda MLR, Barcellos NT, Alencastro PR, Wolff FH, Moreira LB, Gus M, et al. Alcohol drinking pattern: a comparison between HIV-infected patients and individuals from the general population. PLoS One. 2016;11(6):e0158535.

53. Cornell M. Gender inequality: bad for men's health. South Afr J HIV Med. 2013;14(1):12-4

\section{Publisher's Note}

Springer Nature remains neutral with regard to jurisdictional claims in published maps and institutional affiliations.
Ready to submit your research? Choose BMC and benefit from:

- fast, convenient online submission

- thorough peer review by experienced researchers in your field

- rapid publication on acceptance

- support for research data, including large and complex data types

- gold Open Access which fosters wider collaboration and increased citations

- maximum visibility for your research: over $100 \mathrm{M}$ website views per year

At BMC, research is always in progress.

Learn more biomedcentral.com/submissions 